СРАВНИТЕЛЬНЫЙ АНАЛИЗ РЕЗУЛЬТАТОВ КОНКУРСОВ 2019 И 2020 ГГ. НА ПРАВО ПОЛУЧЕНИЯ ГРАНТОВ ПРЕЗИДЕНТА РОССИЙСКОЙ ФЕДЕРАЦИИ ДЛЯ ГОСУДАРСТВЕННОЙ ПОДДЕРЖКИ МОЛОДЫХ РОССИЙСКИХ УЧЕНЫХ КАНДИДАТОВ НАУК И ДОКТОРОВ НАУК

\author{
Б.B. Иванов, дир. центра ФГБНУ НИИ РИНКЦЭ, ibv64@mail.ru \\ C.B. Кристалинская, зам. дир. центра ФГБНУ НИИ РИНКЦЭ, Svetik-kristal@list.ru \\ E.A. Гладышева, нач. отдела ФГБНУ НИИ РИНКЦЭ, gladish@rambler.ru \\ И.С. Кириловская, вед. инж. ФГБНУ НИИ РИНКЦЭ, kiryaira@mail.ru \\ O.B. Шеханова, вед. инж. ФГБНУ НИИ РИНКЦЭ, olgameijin@ya.ru \\ Д.А. Добрынин, инж.-прогр. ФГБНУ НИИ РИНКЦЭ, dobrynin@extech.ru
}

Рецензент: А.И. Мохов

В статье представлен сравнительный анализ результатов конкурсов грантов Президента Российской Федеращии для государственной поддержкки молодых российских ученых 2019 и 2020 г2.: проанализировано распределение победителей конкурсов по областям знаний, федеральным округам, регионам, ведомствам и организациям; приведены обобщенные данные о количестве публикаций победителей конкурсов, индексируемых в межжународных информационно-аналитических системах научного иитирования, по направлениям Стратегии научно-технологического развития Российской Федерации.

Ключевые слова: гранты Президента Российской Федерации, конкурс, молодые российские ученые, кандидаты наук, доктора наук, направления Стратегии научнотехнологического развития Российской Федерации, международные информационноаналитические системы научного цитирования, организационно-техническое обеспечение, информационное сопровождение.

\title{
COMPARATIVE ANALYSIS OF THE RESULTS OF THE 2019 AND 2020 COMPETITIONS FOR THE RIGHT TO RECEIVE GRANTS FROM THE PRESIDENT OF THE RUSSIAN FEDERATION FOR STATE SUPPORT OF YOUNG RUSSIAN SCIENTISTS - DOCTORS OF SCIENCES AND PHILOSOPHY DOCTORS (PH.D.)
}

\author{
B.V. Ivanov, Director of Centre, SRI FRCEC, ibv64@mail.ru \\ S.V. Kristalinskaya, Deputy Director of Centre, SRI FRCEC, Svetik-kristal@list.ru \\ E.A. Gladysheva, Head of Department, SRI FRCEC, gladish@rambler.ru \\ I.S. Kirilovskaya, Leading Engineer, SRI FRCEC, kiryaira@mail.ru \\ O.V. Shekhanova, Leading Engineer, SRI FRCEC, olgameijin@ya.ru \\ D.A. Dobrynin, Software engineer, SRI FRCEC, dobrynin@extech.ru
}

The article presents a comparative analysis of the results of the grant competitions of the President of the Russian Federation for state support of young Russian scientists in 2019 and 2020: the distribution of the winners of the competitions by areas of knowledge, federal districts, regions, departments and organizations is analyzed; the article summarizes data on the number of publications of the winners of competitions, indexed in international information-analytical systems 


\section{of scientific citation, in the areas of the Strategy for scientific and technological development of the Russian Federation.}

Keywords: grants of the President of the Russian Federation, competition, young Russian scientists, doctors of sciences, PhD-s, directions of the Strategy for scientific and technological development of the Russian Federation, international information and analytical systems of scientific citation, organizational and technical support, information support.

В течение последних лет в научно-технической сфере реализуются разнообразные программы поддержки научной молодежи. Проводимые регулярно с 2003 г. конкурсы на право получения грантов Президента Российской Федерации для государственной поддержки молодых российских ученых и ведущих научных школ Российской Федерации (гранты Президента Российской Федерации) занимают ведущее место в ряду таких программ, содействуя закреплению молодых исследователей в ведущих российских научных организациях. Во исполнение приказов Минобрнауки России организационно-техническое и информационное обеспечение деятельности Совета по грантам Президента Российской Федерации для государственной поддержки молодых российских ученых и ведущих научных школ Российской Федерации (Совет по грантам) в рамках данных конкурсов осуществляет ФГБНУ НИИ РИНКЦЭ.

Гранты учреждены Указом Президента Российской Федерации от 09.02.2009 № 146 «О мерах по усилению государственной поддержки молодых российских ученых - кандидатов и докторов наук» и выделяются в соответствии с Постановлением Правительства Российской Федерации от 27.04.2005 № 260 «О мерах по государственной поддержке молодых российских ученых - кандидатов наук и докторов наук и ведущих научных школ Российской Федерации» на конкурсной основе на двухлетний срок. Основная цель выделения грантов поддержка научных исследований молодых российских ученых.

Конкурсы проводятся среди молодых кандидатов наук (MK), возраст которых на момент окончания гранта не превышает 35 лет; молодых докторов наук (МД), возраст которых на момент окончания гранта не превышает 40 лет; ведущих научных школ Российской Федерации (НШ), руководители которых на регулярной основе осуществляют подготовку кандидатов и докторов наук, формируют исследовательские группы для проведения перспективных научных исследований и возраст которых не превышает 50 лет. Конкурсы МК и МД проводятся ежегодно, конкурс НШ - один раз в два года.

Предметом статьи является сравнительный анализ результатов конкурсов 2019 и 2020 гг. С учетом того, что по регламенту в 2019 г. конкурс НШ не проводился, для корректного сравнения рассмотрены конкурсы для молодых ученых (МК и МД).

В заявочную кампанию конкурсов 2019 г. зарегистрировались 3645 кандидатов наук и 298 докторов наук; представили полный комплект конкурсных документов 2460 кандидатов наук и 224 докторов наук. С учетом отклонения заявок по формальному признаку, к участию в конкурсах допущены 2429 кандидатов наук и 221 доктор наук.

В 2020 г. зарегистрировались 2243 кандидатов наук и 216 докторов наук; полный комплект конкурсных документов представлен 1525 кандидатами наук и 155 докторами наук. К участию в конкурсах допущены 1509 кандидатов наук и 152 доктора наук.

По результатам работы экспертных комиссий и в соответствии с предложениями Совета по грантам Конкурсной комиссией Минобрнауки России в конкурсах 2019 г., как и в конкурсах 2020 г., определены победителями 400 кандидатов наук и 60 докторов наук.

Особенностью конкурса 2020 г. стало распределение участников не только по областям знаний, но и по направлениям Стратегии научно-технологического развития Российской Федерации (направления СНТР).

В конкурсах 2020 г. соискатели относили свои заявки к тому или иному направлению СНТР, сведения по победителям конкурсов МК-2020 и МД-2020 приведены в табл. 1. Наибольшее число заявок представлено по направлению «Переход к передовым цифровым, 
интеллектуальным производственным технологиям, роботизированным системам, новым материалам и способам конструирования, создание систем обработки больших объемов данных, машинного обучения и искусственного интеллекта».

Таблица 1

Распределение участников конкурса 2020 г. по направлениям СНТР (число участников)

\begin{tabular}{|c|c|c|c|c|}
\hline № & Направление СНТР & MK-2020 & МД-2020 & $\%$ \\
\hline 1 & $\begin{array}{l}\text { Переход к передовым цифровым, интеллектуальным производствен- } \\
\text { ным технологиям, роботизированным системам, новым материалам и } \\
\text { способам конструирования, создание систем обработки больших объ- } \\
\text { емов данных, машинного обучения и искусственного интеллекта }\end{array}$ & 133 & 21 & 34 \\
\hline 2 & $\begin{array}{l}\text { Возможность эффективного ответа российского общества на большие } \\
\text { вызовы с учетом взаимодействия человека и природы, человека и тех- } \\
\text { нологий, социальных институтов на современном этапе глобального } \\
\text { развития, в том числе применяя методы гуманитарных и социальных } \\
\text { наук }\end{array}$ & 67 & 6 & 16 \\
\hline 3 & $\begin{array}{l}\text { Переход к персонализированной медицине, высокотехнологичному } \\
\text { здравоохранению и технологиям здоровьесбережения, в том числе за } \\
\text { счет рационального применения лекарственных препаратов (прежде } \\
\text { всего антибактериальных) }\end{array}$ & 66 & 13 & 17 \\
\hline 4 & $\begin{array}{l}\text { Переход к экологически чистой и ресурсосберегающей энергетике, } \\
\text { повышение эффективности добычи и глубокой переработки углево- } \\
\text { дородного сырья, формирование новых источников, способов тран- } \\
\text { спортировки и хранения энергии }\end{array}$ & 55 & 4 & 13 \\
\hline 5 & $\begin{array}{l}\text { Переход к высокопродуктивному и экологически чистому агро- и аква- } \\
\text { хозяйству, разработка и внедрение систем рационального примене- } \\
\text { ния средств химической и биологической защиты сельскохозяйствен- } \\
\text { ных растений и животных, хранение и эффективная переработка } \\
\text { сельскохозяйственной продукции, создание безопасных и качествен- } \\
\text { ных, в том числе функциональных, продуктов питания }\end{array}$ & 36 & 7 & 9 \\
\hline 6 & $\begin{array}{l}\text { Противодействие техногенным, биогенным, социокультурным угро- } \\
\text { зам, терроризму и идеологическому экстремизму, а также киберугро- } \\
\text { зам и иным источникам опасности для общества, экономики и госу- } \\
\text { дарства }\end{array}$ & 21 & 6 & 6 \\
\hline 7 & $\begin{array}{l}\text { Связанность территории Российской Федерации за счет создания ин- } \\
\text { теллектуальных транспортных и телекоммуникационных систем, } \\
\text { а также занятия и удержания лидерских позиций в создании между- } \\
\text { народных транспортно-логистических систем, освоении и использо- } \\
\text { вании космического и воздушного пространства, Мирового океана, } \\
\text { Арктики и Антарктики }\end{array}$ & 22 & 3 & 5 \\
\hline
\end{tabular}

Списки победителей конкурсов публикуются на сайте Совета по грантам. В 2019 г. публикация производилась по областям знаний, в 2020 г. - по направлениям СНТР.

Пример публикации информации по победителям МК-2019 приведен на рис. 1, по победителям МК-2020 - на рис. 2.

Сравнительный анализ показал, что конкурсы 2020 г. были не такими многочисленными по количеству участников, как конкурсы 2019 г., что обусловлено, кроме прочего, малым интервалом между данными мероприятиями, который составил, по объективным причинам, около девяти месяцев. 


\section{Совет по грантам Президента Российской Федерации}

для государственной поддержки молодых российских ученых

и по государственной поддержке ведущих научных школ Российской Федерации

Победители конкурса 2019 года по государственной поддержке молодых российских ученых-кандидатов наук

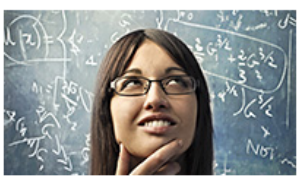

МАТЕМАТИКА И МЕХАНИКА

Победителей: 27

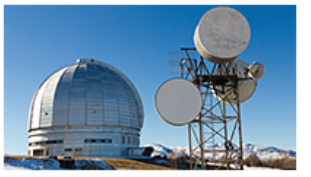

ФИЗИКА И АСТРОНОМИЯ

Победителей: 50

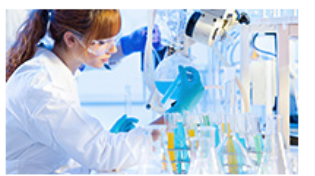

ХИМИЯ, НОВЫЕ МАТЕРИАЛЫ И ХИМИЧЕСКИЕ ТЕХНОЛОГИИ

Победителей: 55

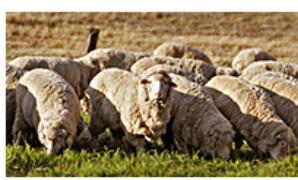

БИОЛОГИЯ И НАУКИ О ЖИЗНИ

Победителей: 37

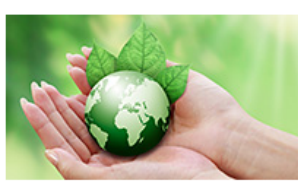

НАУКИ О ЗЕМЛЕ, ЭКОЛОГИИ И РАЦИОНАЛЬНОМ ПРИРОДОПОЛЬЗОВАНИИ

Победителей: 35

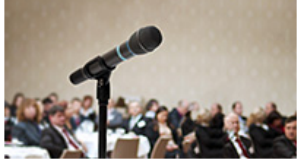

ОБЩЕСТВЕННЫЕ И ГУМАНИТАРНЫЕ НАУКИ

Победителей: 66

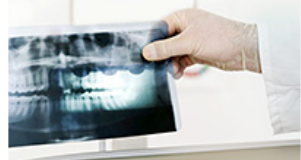

МЕДИЦИНА

Победителей: 21

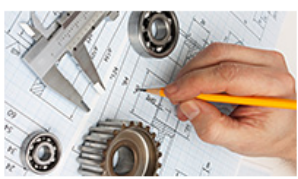

ТЕХНИЧЕСКИЕ И ИНЖЕНЕРНЫЕ НАУКИ

Победителей: 80

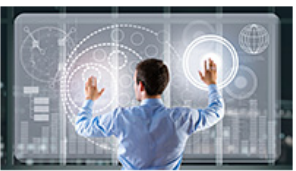

ИНФОРМАЦИОННО-ТЕЛЕКОММУНИКАЦИОННЫЕ СИСТЕМЫ И ТЕХНОЛОГИИ

Победителей: 17

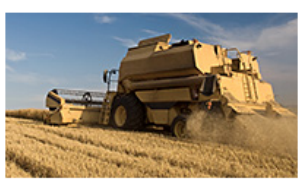

СЕЛЬСКОХОЗЯЙСТВЕННЫЕ НАУКИ

Победителей: 12

Рис. 1. Пример публикации списков победителей МК-2019 по областям знаний 


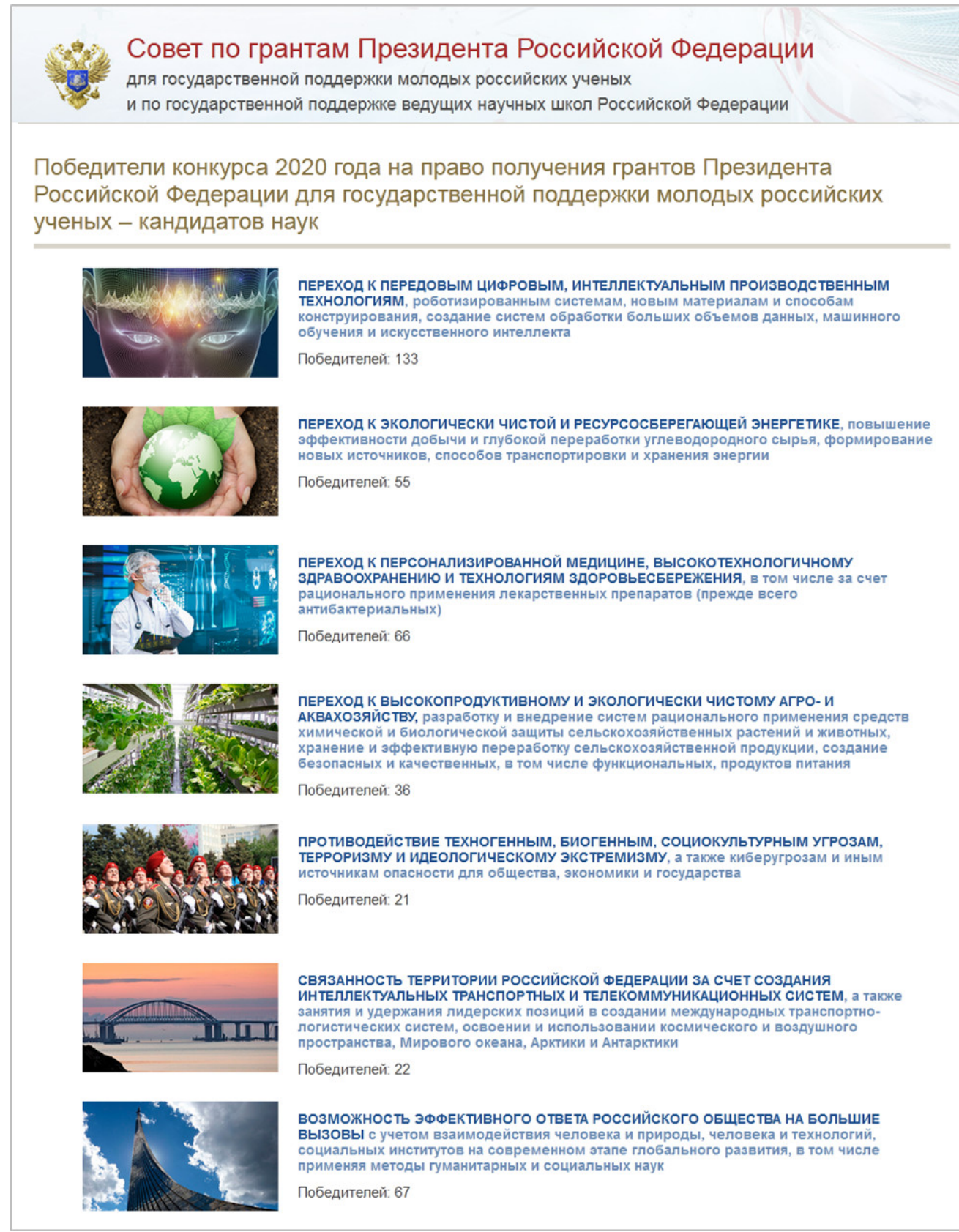

Рис. 2. Пример публикации списков победителей МК-2020 по направлениям СНТР

Сравнительный анализ данных в разрезе областей знаний показывает, что распределение победителей конкурсов по годам существенно не меняется. Наибольшую активность в конкурcax 2019 и 2020 гг. проявили ученые в таких областях, как «Технические и инженерные науки», «Общественные и гуманитарные науки» и «Химические технологии», а наименьшую «Сельскохозяйственные науки», «Математика и механика» и «Информационные технологии».

Сведения о распределении победителей конкурсов по областям знаний представлены на рис. 3. 


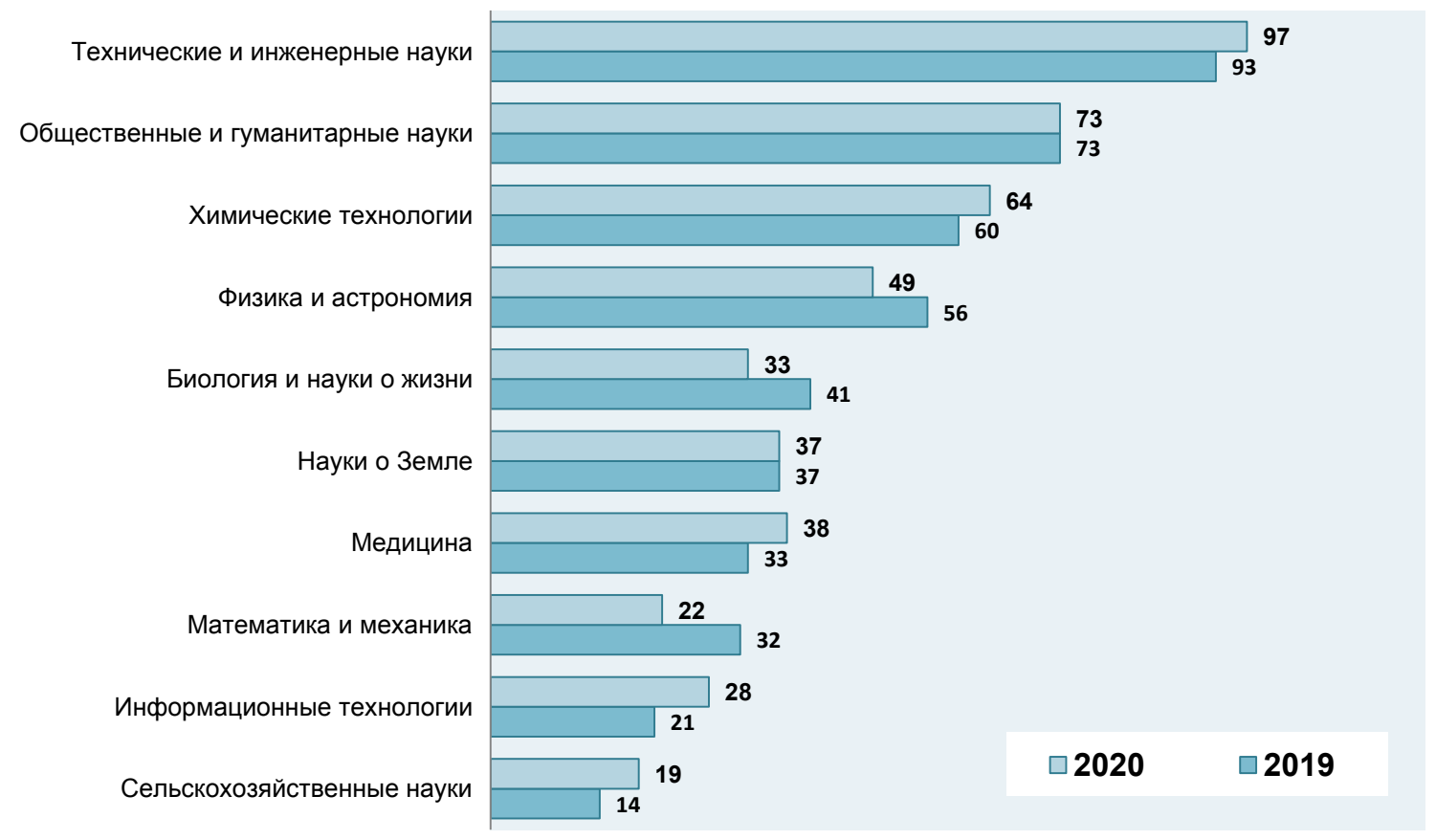

Рис. 3. Распределение победителей конкурсов 2019 и 2020 гг. по областям знаний

В конкурсах приняли участие представители всех федеральных округов страны. Данные о распределении победителей конкурсов по федеральным округам представлены на рис. 4.

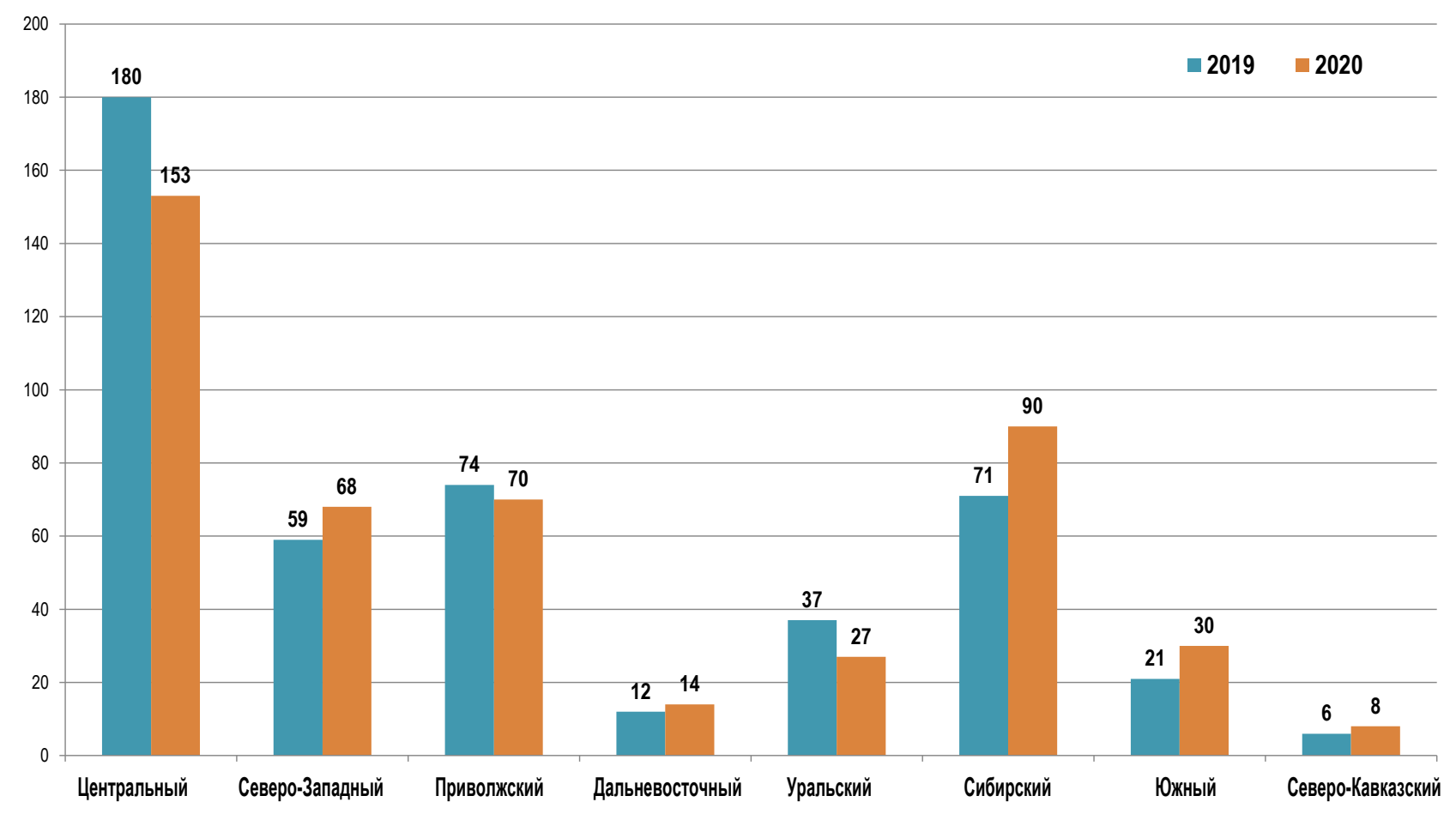

Рис. 4. Распределение победителей конкурсов 2019 и 2020 гг. по федеральным округам 
Наибольшее число победителей - в Центральном, Сибирском, Приволжском и СевероЗападном округах. Однако количество победителей в Центральном и Уральском округах в 2020 г. уменьшилось, а в Сибирском, Северо-Западном и Южном округах - увеличилось.

Результаты сравнительного анализа конкурсов по регионам представлены на рис. 5. Очевидно, что лидирующие позиции в конкурсах занимают Москва и Санкт-Петербург, однако если количество победителей от Санкт-Петербурга в конкурсе 2020 г. увеличилось почти на четверть, то от Москвы, наоборот, немного снизилось. В ряде субъектов Российской Федерации в 2020 г. наметилась тенденция к увеличению числа победителей в два или даже в три раза (по сравнению с 2019 г.). К ним относятся Белгородская, Волгоградская, Воронежская области, а также Алтайский край и Пермский край. Остальные регионы в целом по конкурсам имеют стабильные показатели.

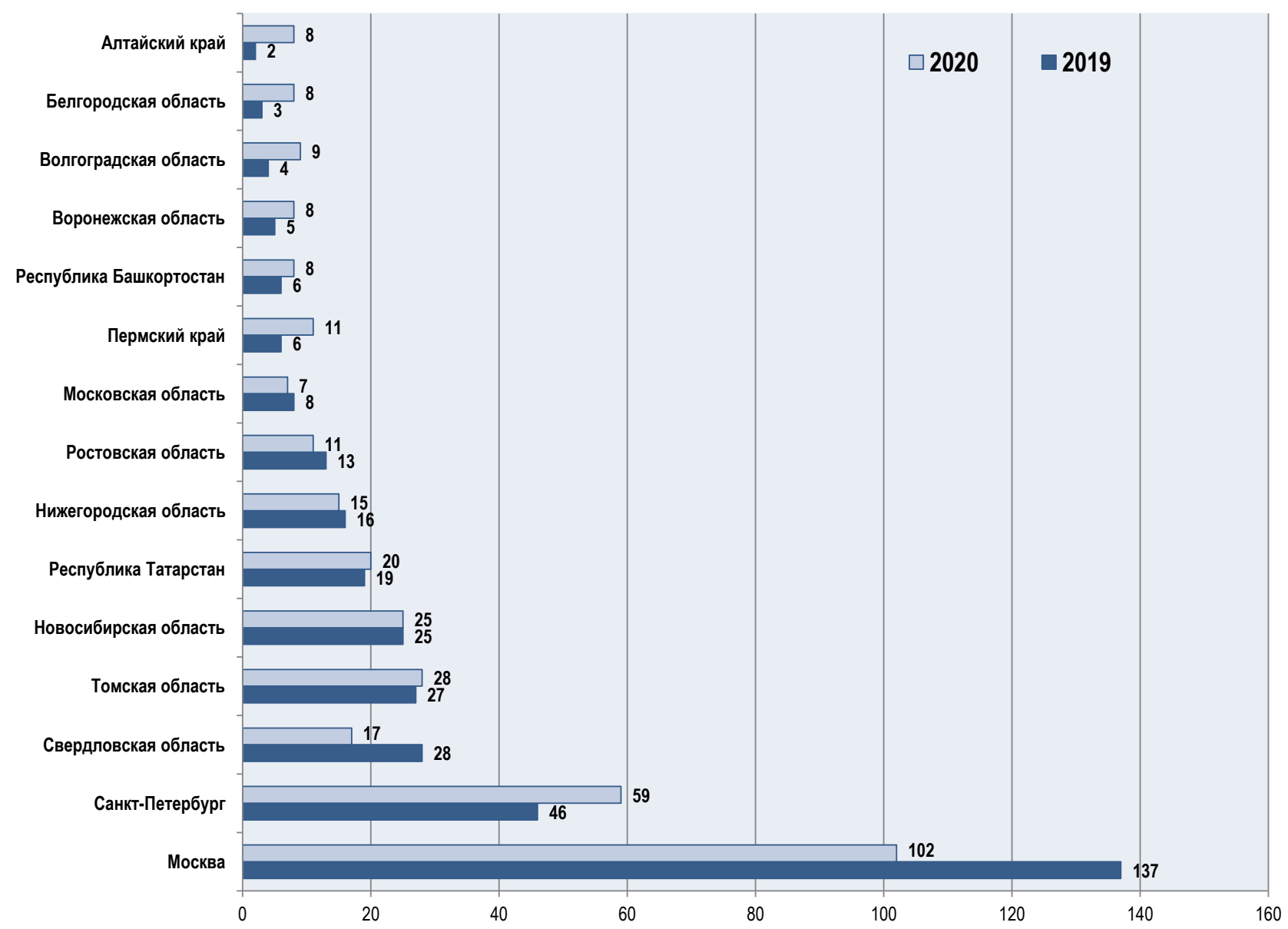

Рис. 5. Распределение победителей конкурсов 2019 и 2020 гг. по регионам

Представляет интерес и степень участия в конкурсах главных распорядителей бюджетных средств (ГРБС).

Представители организаций, подведомственных Минобрнауки России, составляют около $80 \%$ от общего числа участников/победителей конкурсов. Сведения о распределении победителей конкурсов по другим ГРБС представлены на рис. 6.

Наиболее активное участие в конкурсах приняли молодые ученые Минздрава России, МГУ им. М.В. Ломоносова, СПбГУ и Минсельхоза России. 


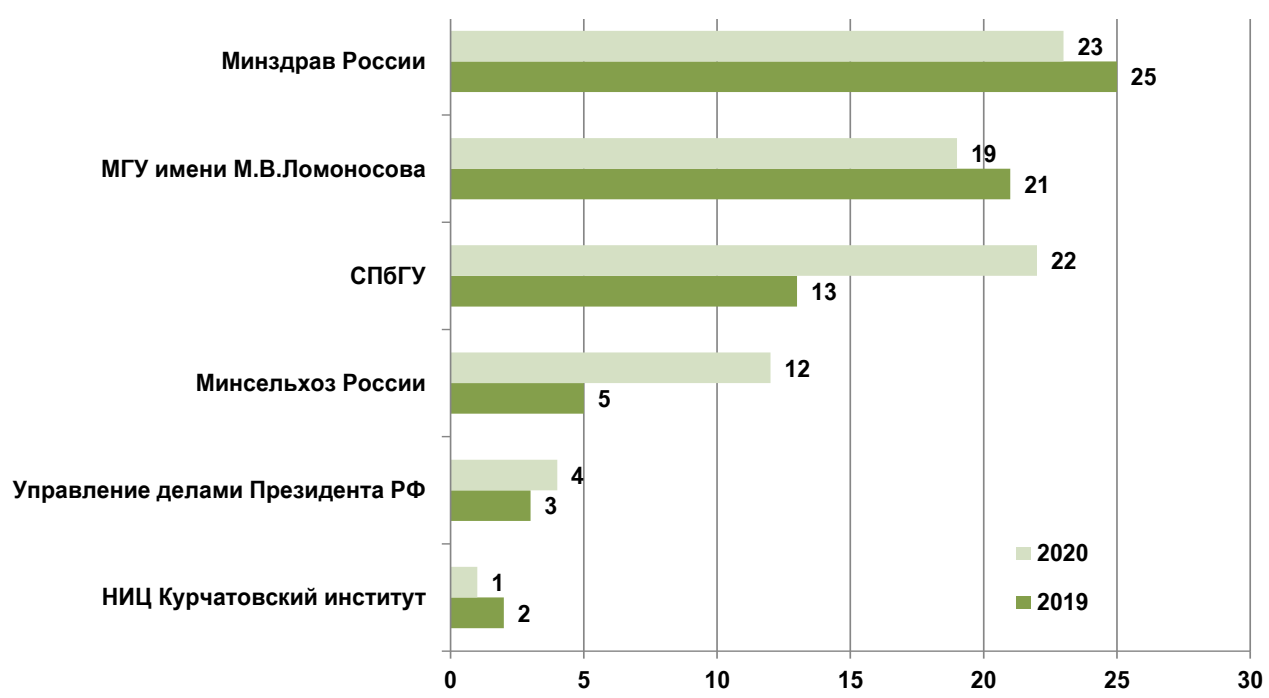

Рис. 6. Распределение победителей конкурсов 2019 и 2020 гг. по ГРБС

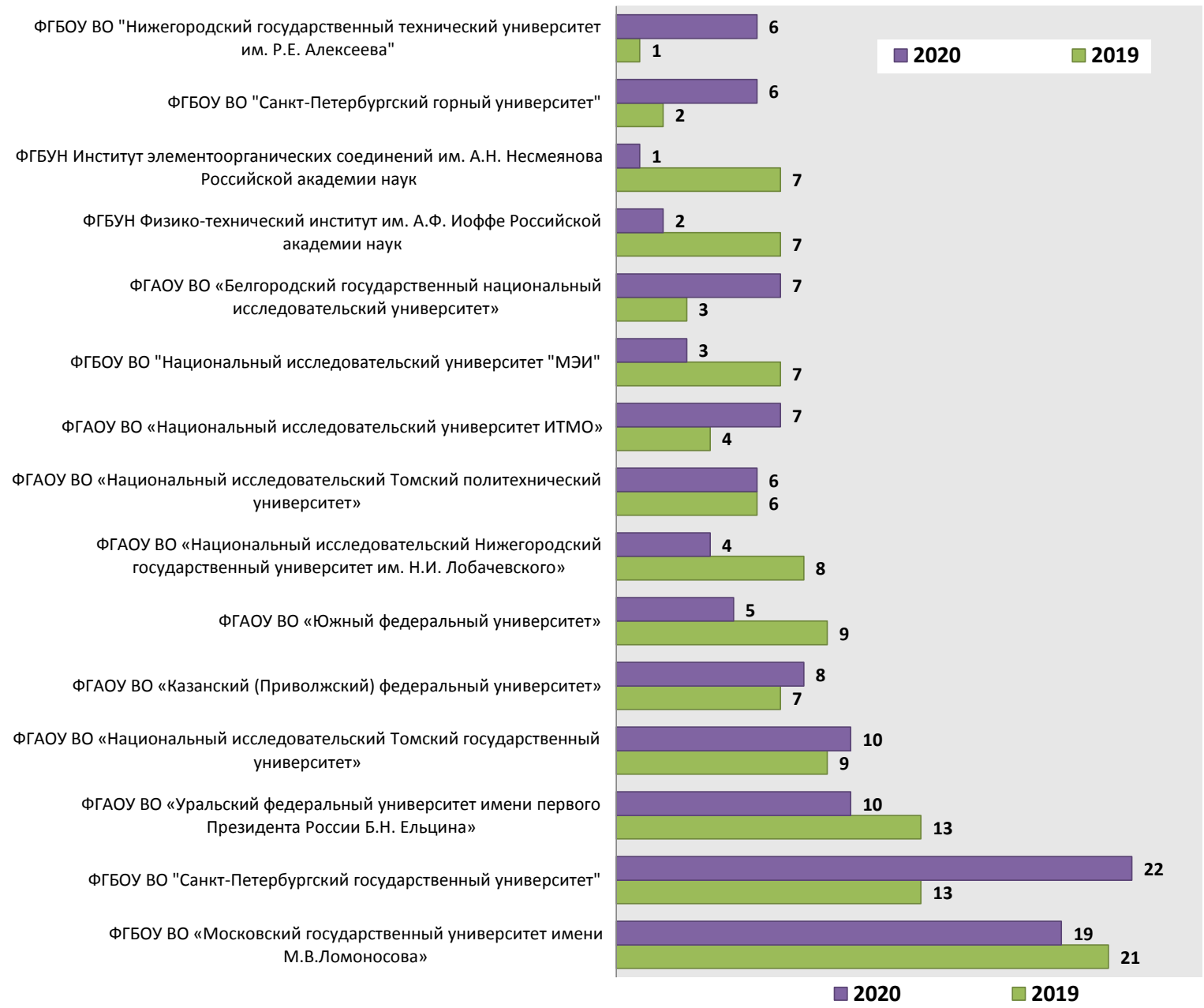

Рис. 7. Распределение победителей конкурсов 2019 и 2020 гг. по организациям 
Результаты анализа распределения победителей конкурсов по организациям, представившим наибольшее число заявок, представлены на рис. 7. Наиболее активное участие в конкурсах приняли молодые ученые МГУ им. М.В. Ломоносова и СПбГУ. Примечательно, что в 2020 г. показатели активности СПбГУ резко увеличились. Аналогичная тенденция наблюдается и у ряда других организаций, например Санкт-Петербургского горного университета, Нижегородского государственного технического университета им. Р.Е. Алексеева, Белгородского государственного национального исследовательского университета и Национального исследовательского университета ИТМО.

Однако некоторые организации, наоборот, в конкурсах 2020 г. снизили активность по сравнению с предыдущим годом, - например, Национальный исследовательский университет «МЭИ», Физико-технический институт им. А.Ф. Иоффе, Институт элементоорганических соединений им. А.Н. Несмеянова.

Одной из актуальных задач при проведении конкурсов является оценка показателей публикационной активности победителей. Сводные данные по конкурсам МК и МД за 2019 и 2020 гг. о количестве представленных публикаций, индексируемых в международных информационно-аналитических системах научного цитирования WoS и Scopus, приведены в табл. 2.

Таблица 2

Обобщенные сведения о количестве публикаций победителей конкурсов МК и МД, индексируемых в WoS и Scopus (за 2019 и 2020 гг.)

\begin{tabular}{|c|c|c|c|c|}
\hline \multirow{3}{*}{ Область знаний } & \multicolumn{2}{|c|}{ Конкурс 2019 г. } & \multicolumn{2}{|c|}{ Конкурс 2020 г. } \\
\hline & \multicolumn{4}{|c|}{ Количество публикаций } \\
\hline & WoS & Scopus & WoS & Scopus \\
\hline Математика и механика & 251 & 345 & 120 & 154 \\
\hline Физика и астрономия & 1049 & 1228 & 617 & 711 \\
\hline Химия & 840 & 841 & 755 & 810 \\
\hline Биология & 494 & 423 & 260 & 269 \\
\hline Науки о Земле & 219 & 308 & 189 & 274 \\
\hline Общественные науки & 175 & 191 & 169 & 162 \\
\hline Медицина & 152 & 182 & 189 & 265 \\
\hline Технические науки & 1146 & 1561 & 440 & 832 \\
\hline Информатика & 215 & 331 & 196 & 304 \\
\hline Сельскохозяйственные науки & 77 & 87 & 62 & 84 \\
\hline
\end{tabular}

В конкурсах 2020 г. публикационная активность победителей снизилась почти вдвое в таких областях знаний, как «Математика и механика», «Физика и астрономия» и «Технические науки», а в области «Медицина», наоборот, возросла. В остальных областях количество публикации остается примерно одинаковым.

Проведенный анализ результатов конкурсов 2019 и 2020 гг. свидетельствует о сохранении интереса молодых ученых к такой форме государственной поддержки отечественной науки, как гранты Президента Российской Федерации. В целом реализация данного инструмента способствует решению таких важных государственных задач, как закрепление талантливой молодежи в российских научных организациях и привлечение молодых ученых к проведению научных исследований.

Статья подготовлена по материалам работ, выполненных ФГБНУ НИИ РИНКЦЭ в рамках государственного задания № 075-01394-20-02. 